\title{
Theoretical Studies of Hydrolysis and Stability of
}

\section{Polyacrylamide Polymers}

\author{
Qisheng Ma ${ }^{1,2}$, Patrick J. Shuler ${ }^{1}$, Carl W. Aften ${ }^{1}$, Yongchun Tang ${ }^{2, *}$ \\ ${ }^{1}$ ChemEOR Inc. Covina, CA 91722 \\ ${ }^{2}$ Power Environmental Energy Research Institute, Covina, CA 91722
}

*: Corresponding Author

Yongchun Tang

Power Environmental Energy Research Institute

738 Arrow Grand Circle, Covina, CA 91722, USA

Tel. (626) 858-5077

Fax: (626) 858-9250

E-mail: tang@peeri.org 


\begin{abstract}
Thermal stability of water-soluble polyacrylamide (PAM) and partially hydrolyzed polyacrylamide (HPAM) polymers under various solution conditions have been studied utilizing Quantum Mechanics Density Functional Theory (DFT) computational modeling method. The hydrolysis reaction of the amide group (AM) to form acrylic acid (AA) is significantly affected by the $\mathrm{pH}$ of solution and the presence of cationic species such as $\mathrm{Ca}^{2+}$. Without catalyzed, PAM is thermally stable with transition barriers as high as 50 $\mathrm{kcal} / \mathrm{mol}$. Both acid and base can catalyze the hydrolysis reaction by lowering activation energies with more than $10 \mathrm{kcal} / \mathrm{mol}$. Formation of the 6-membered ring transition state (TS) structure arising from the assist of a second water or an ammonia molecule yields a lower enthalpic energy, which is sufficient to overcome the entropic penalty for bring three molecular species together for reactions. Ammonia/ammonium as products of hydrolysis also catalyze the reaction, rendering an auto-accelerated amide hydrolysis kinetics. The divalent $\mathrm{Ca}^{+2}$ cation not only interacts with carboxylic groups on HPAM to alter their rheological and phase behaviors, but also catalyzes the hydrolysis reaction to increase the degree of hydrolysis of HPAM. These results provide theoretical insights for molecular modifications of PAM/HAPM for their high-temperature (HT) and highsalinity (HS) applications.
\end{abstract}




\section{INTRODUCTION}

Water-soluble polyacrylamide (PAM) and partially hydrolyzed polyacrylamide (HPAM) polymers are among the most commonly used chemicals in oilfield applications. In polymer-augmented water-flooding Enhanced Oil Recovery (EOR) processes, HPAM polymers are often used as mobility-control agents to increase the viscosity of stimulation fluids in order to improve the sweep efficiency [1-3]. In hydraulic fracturing reservoir treatments, high molecular-weight PAM/HPAM are used as friction reducers in order to minimize pumping power demands and to provide sufficient proppant-carrying capacity of fracturing fluids [4-6]. However, applications of PAM/HPAM in high-temperature (HT) $\left(>90^{\circ} \mathrm{C}\right)$ and high-salinity (HS) $(100,000 \sim 200,000 \mathrm{ppm})$ reservoir conditions are limited primarily because of their thermal instability [7-9]. This is particularly the case when there are certain amounts of divalent cations $\left(\mathrm{Ca}^{2+}, \mathrm{Mg}^{2+}, \mathrm{Sr}^{2+}\right.$ and etc. $)$ in reservoir brines [10-12]. It is well documented that cationic species strongly interact with HPAM, resulting in the rapid phase separation through formation of gel or precipitate $[7,13,14]$. Multivalent cations are easily chelated by HPAM chains to form a stable cross-linking complexes such as $\mathrm{CaO}_{4}$ [15]. A recent laboratory study conducted by Seright et al. [16] indicated that a PAM polymer can remain thermally stable in the absence of dissolved oxygen and divalent cations, so that the HPAM solution is projected to maintain at least half of their original viscosity for over 8 years at $100{ }^{\circ} \mathrm{C}$ and about 2 years at $120{ }^{\circ} \mathrm{C}$. Moradi-Araghi and Doe [12] shown that stability limitations of PAM significantly varied in brines containing different divalent cations $\left(<96{ }^{\circ} \mathrm{C}\right.$ for $270 \mathrm{mg} / \mathrm{L} ;<88{ }^{\circ} \mathrm{C}$ for 500 $\mathrm{mg} / \mathrm{L}$; and $<75{ }^{\circ} \mathrm{C}$ for $2,000 \mathrm{mg} / \mathrm{L}$ ). These observation indicate significant adverse effects of divalent cations on the stability of PAM/HPAM polymers.

The dangling amide group of the PAM polymer could be hydrolyzed to form an acrylic acid that is subject to the easier interaction with cations. Chemistry regarding the amide hydrolysis is very rich and has been considered as an important modeled reaction for the enzymatic cleavage of peptide bonds [17-19]. Mechanism and kinetics of the amide hydrolysis under different conditions have been extensively studied from both experimental and theoretical aspects. For example, theoretical studies of the basecatalyzed amide hydrolysis reaction predicted a $20 \sim 30 \mathrm{kcal} / \mathrm{mol}$ transition barrier that is in good agreement with experimental measurements $[20,21]$. A two-step mechanism 
involving the nucleophilic attack of hydroxide ion on the carbonyl carbon to form a tetrahedral intermediate as the first step, followed by the release of an ammonia molecule, has been established [22-26]. Acid-promoted amide hydrolysis reactions have also been studied [18, 27-30]. O- and N-protonation pathways were found to compete with either other, with similar activation energies of $\sim 20 \mathrm{kcal} / \mathrm{mol}$, which are consistent with the experimental value of $21.5 \mathrm{kcal} / \mathrm{mol}[31,32]$.

Under the neutral condition, interaction of the amide group with a water molecule is much more difficult, without assisted or catalyzed. Both concerted and stepwise pathways yield quite high activation energies (>50 kcal/mol) in gas-phase and in aqueous phase [28, 33-35]. The reverse hydrolysis reaction has also been studied, and activation energies are also very high [36-38]. On the other hand, Oie et al. [37] found that the assistance of an additional ammonia molecule could substantially lower activation barriers for both of stepwise $(-10 \mathrm{kcal} / \mathrm{mol})$ and concerted $(-2 \mathrm{kcal} / \mathrm{mol})$ pathways. Mechanisms of the water-promoted amide hydrolysis by a second water molecule have also been proposed [29, 33, 39-42]. The presence of additional water molecule might reduce activation energies in range of $15 \sim 20 \mathrm{kcal} / \mathrm{mol}$. Such a water assistance effect is found to be more profound in the acid-promoted reaction [33], i.e., the O-protonation facilitates the water-assisting hydrolysis reaction, such that to significantly lower the activation energy by as much as $35 \mathrm{kcal} / \mathrm{mol}$.

Despite intensively studies on the amide hydrolysis, there is relatively less attention paid to understand cationic effects on the reaction mechanism. In particular, there still is a lack of fundamental understanding on why the presence of different concentrations of $\mathrm{Ca}^{+2}$ could have such adverse effects on the thermal stability of PAM, which is considered as the main factor limiting applications of PAM/HPAM under hightemperature/high-salinity (HT/HS) environment. Therefore, our objective is to conduct a systematic study of the amide hydrolysis under different conditions, with an emphasis on effects of divalent cations. Molecular simulations based on Density Functional Theory (DFT) methods are applied to map out possible reaction pathways and to determine the configuration energies of all stable, intermediate and transition states. Our results indicate that, in addition to aggravate precipitation, divalent cations in aqueous solution might also catalyze the amide hydrolysis reaction. These results offer a plausible explanation to 
the laboratory and field observations that the thermal stability of PAM polymers is significantly lowered when there are higher concentrated divalent cations in brines.

\section{Computational methods}

PAM is composed of repeating units of the acrylamide (AM) (Figure 1(a)). At elevated temperature, some of amide groups undergo the hydrolysis reaction to become carboxylic groups (Figure 1(b)). The degree of hydrolysis $\tau$ of HPAM (Figure 1(c)) is defined as:

$$
\tau=\frac{Y}{X+Y} ; \quad 0 \leq \tau \leq 1
$$

Where $\mathrm{X}$ and $\mathrm{Y}$ are numbers of amide and carboxylic groups in polymer. Because our studies mainly focus on the hydrolysis reaction of the amide group, we model the PAM with a dangling $-\mathrm{CONH}_{2}$ group attaching to the middle carbon of the $\mathrm{C}_{5}$ molecule. Therefore we have neglected the possible neighbor group interactions in this study.

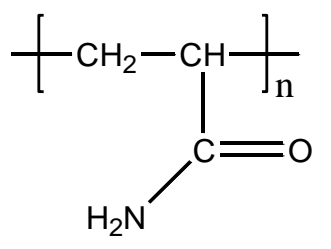

Polyacrylamide (PAM)

(a)

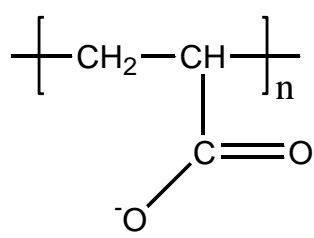

Hydrolyzed PAM

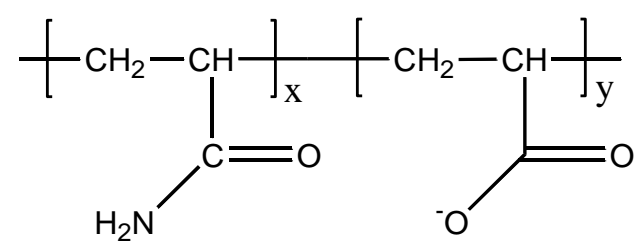

Partially Hydrolyzed Polyacrylamide (HPAM)

(c)

Figure 1: Molecular Structures of (a) Polyacrylamide (PAM), (b) Hydrolyzed Polyacrylamide, and (c) Partially Hydrolyzed Polyacrylamide (HPAM)

Molecular geometry of all reactants, intermediates, transition states and products are fully optimized using the quantum mechanics DFT/B3LYP/6-31G** method. Since there are mainly organic elements $(\mathrm{C}, \mathrm{O}, \mathrm{N}$, and $\mathrm{H})$ involved, such a level of computation has been well established producing reasonable results for both energetic and geometric information of chemical reactions. Thermodynamic calculations were carried out to take the Zero-Point Energy (ZPE) correction and the temperature dependence into accounts. All configurations have been identified as local minima (no imaginary vibrational modes for stationary states and unique imaginary vibrational frequency for a transition state). The water solvation effect is also considered using the continuum-solvation approach by solving the Poisson-Bolzmann equation with a default dielectric constant of 80.37 and a 
probe radius of $1.40 \AA$ for water. From previous studies, we found no significant deviation in structures between the gas-phase and continuum-solvation phase, so a single point solvation energy correction is considerably sufficient. Therefore, the molecular geometry is only optimized in gas-phase, while the solvation energy determined from the gas-phase geometry is included as an additional energy term $\mathrm{E}_{\text {sol. }}$. The Gibbs' free energy is determined from:

$$
\Delta G_{T}=E_{0}+Z P E+\delta H_{T}-T \delta S_{T}+E_{s o l}
$$

where $\mathrm{E}_{0}$ is the total gas-phase electronic energy at temperature $\mathrm{T}=0 \mathrm{~K}, \mathrm{ZPE}$ is the quantum mechanics Zero-Point Energy (ZPE) correction, $\delta \mathrm{H}_{\mathrm{T}}$ and $\delta \mathrm{S}_{\mathrm{T}}$ are the enthalpy and entropy changes from temperature $=0$ to $\mathrm{T}$, and $\mathrm{E}_{\mathrm{sol}}$ is the single solvation energy correction. All calculated energies are taken at the ambient condition $(\mathrm{T}=298.15 \mathrm{~K}, \mathrm{P}=$ $1 \mathrm{~atm})$. And the commercial Quantum Mechanical computational software, Jaguar was used.

\section{Results and Discussions}

\subsection{Hydrolysis of PAM under the Neutral Condition}

Under neutral conditions, two competitive reaction paths are considered (Figure 2). The two-step pathway (a) features a nucleophilic addition of one water molecule to form a T-complex through transition state $\mathrm{TS}_{1}$, followed by the ammonia elimination via transition state $\mathrm{TS}_{2}$. The concerted pathway (b) is characterized by simultaneous $\mathrm{C}-\mathrm{O}$ and $\mathrm{N}-\mathrm{H}$ bond formations, and the C-N bond breaking through transition state $\mathrm{TS}_{3}$. For both pathways, the net reaction is the same:

$$
\mathrm{R}-\mathrm{CONH}_{2}+\mathrm{H}_{2} \mathrm{O} \rightarrow \mathrm{R}-\mathrm{COOH}+\mathrm{NH}_{3}
$$

Calculated transition barriers of both reaction pathways are very high (>50 kcal/mol), indicating that the hydrolysis of PAM under the neutral condition is difficult.

\subsection{The General Base-Catalyzed Mechanism}

The general base-catalyzed mechanism is well-documented, whereas a strong basic aqueous solution (the hydroxide $\mathrm{OH}^{-}$) is required.

$$
\mathrm{R}-\mathrm{CONH}_{2}+\mathrm{OH}^{-} \rightarrow \mathrm{R}-\mathrm{COO}^{-}+\mathrm{NH}_{3}
$$

The two-step stepwise pathways with the first step of the nucleophilic addition of an $\mathrm{OH}^{-}$group onto the carbonyl carbon with a transition barrier of $22.3 \mathrm{kcal} / \mathrm{mol}\left(\mathrm{TS}_{4}\right)$, followed by the ammonia elimination with a transition barrier of $31.5 \mathrm{kcal} / \mathrm{mol}\left(\mathrm{TS}_{5}\right)$ 
(Figure 3). Our calculated results are in general agreement with the experimental data by Guthrie [20] in where they found transition energies are in range of $20 \sim 30 \mathrm{kcal} / \mathrm{mol}$ at $25 \sim 100{ }^{\circ} \mathrm{C}$ for the base-catalyzed amide hydrolysis.

\subsection{Acid-Catalyzed Mechanism - N-Protonation vs. O-Protonation}

Under the acidic condition, hydrolysis could be initiated from either the $\mathrm{N}$ protonation (proton attacking the $\mathrm{NH}_{2}$ group) or O-protonation (proton attacking the carbonyl oxygen) (Figure 4). Our results indicate that both $\mathrm{O}$ - and N-protonation pathways have similar transition barriers of $>40 \mathrm{kcal} / \mathrm{mol}$. The initial O-protonation is more energetically favorable with a formation energy of $-8.7 \mathrm{kcal} / \mathrm{mol}$ compared to the $0.8 \mathrm{kcal} / \mathrm{mol}$ for that of $\mathrm{N}$-protonation. However, the transition barrier of the nucleophilic addition along the O-protonation pathway is $37.5+8.7=45.2 \mathrm{kcal} / \mathrm{mol}$ which is slightly higher than the N-protonation pathway $41.0+0.8=41.8 \mathrm{kcal} / \mathrm{mol}$.

\subsection{Water-Assisted Concerted Mechanism under the Neutral Condition}

The concerted pathway under the neutral condition (ref. Figure 2 (b)) involves a 4membered ring structure in the transition state, which is typically more energy-intensive. One possible path having a lower transition barrier is with the assist of an additional water molecule to form a 6-membered ring transition state (Figure 5). Normally it requires a large entropy penalty to bring together of three molecular species for reaction. On the other hand, the formation of a 6-member ring structure facilitates the prton transfer and rearrangement to lower the enthalpy barrier. The final Gibbs' energy gain/loss will be determined from the competition of enthalpy and entropy changes. In

this case, the formation of the 6-membered ring transition state lowers the overall transition barrier $(42.4 \mathrm{kcal} / \mathrm{mol})$, compared to $57.8 \mathrm{kcal} / \mathrm{mol}$ for the non-assisted neutral pathways. The overall reaction of the water-assisted hydrolysis is expressed as follow:

$$
\mathrm{R}-\mathrm{CONH}_{2}+\mathrm{H}_{2} \mathrm{O}+\mathbf{H}_{2} \mathbf{O} \rightarrow \mathrm{R}-\mathrm{COOH}+\mathrm{NH}_{3}+\mathbf{H}_{2} \mathbf{O}
$$

Herein, the second water molecule (in bold) acts as an aid (catalyst) to lower the transition barrier, without being consumed or transformed.

\subsection{Auto-Accelerated Hydrolysis Mechanism - Ammonia-Assisted Pathways}

Analogous to the neutral water-assist pathway, the ammonia-assisted mechanism has also been considered (Figure 6). Both the concerted and stepwise pathways have the same overall reaction: 


$$
\mathrm{R}-\mathrm{CONH}_{2}+\mathrm{H}_{2} \mathrm{O}+\mathbf{N H}_{3} \rightarrow \mathrm{R}-\mathrm{COOH}+\mathrm{NH}_{3}+\mathbf{N H}_{3}
$$

Here again, the ammonia molecule aids the reaction similar to the water molecule in the water-assisted mechanism. For the concerted pathway, the energy-lowering effect of the ammonia-assisted pathway $(46.8 \mathrm{kcal} / \mathrm{mol})$ is relatively weaker than the water-assisted pathway (42.4 kcal/mol, ref. Figure 5). The stepwise pathway has the lower transition barrier $(37.8 \mathrm{kcal} / \mathrm{mol})$ than the concerted pathway $(46.8 \mathrm{kcal} / \mathrm{mol})$. A special feature of the ammonia-assisted pathway is that the ammonia itself is the end product of reaction. This suggests that the amide hydrolysis will be an auto-accelerated reaction, i.e., the formation of the ammonia as a product could also act as a catalyst to increase the reaction rate of hydrolysis.

\subsection{Protonated Water-Assisted Mechanism}

The water-assisted mechanism can have more profound impacts on the amide hydrolysis under the acidic condition. A protonated water-assisted reaction is initiated by O-protonation, followed by the 6-membered ring transition state (Figure 7). The overall reaction is:

$$
\mathrm{R}-\mathrm{CONH}_{2}+\mathrm{H}_{3} \mathrm{O}^{+}+\mathbf{H}_{2} \mathbf{O} \rightarrow \mathrm{R}-\mathrm{COOH}+\mathrm{NH}_{4}{ }^{+}+\mathbf{H}_{2} \mathbf{O}
$$

The transition barrier is significantly lowered, with the $18.75 \mathrm{kcal} / \mathrm{mol}\left(\mathrm{TS}_{14}\right)$ higher than the initial reactant configuration. Even if we take into account of $-8.7 \mathrm{kcal} / \mathrm{mol}$ energygain from O-protonation, the overall transition barrier of $27.5 \mathrm{kcal} / \mathrm{mol}$ is still very energetically favorable.

\subsection{Ammonium Catalyzed Water-Assisted Mechanism}

The positively charged ammonium cation $\left(\mathrm{NH}_{4}{ }^{+}\right)$can also attack on the carbonyl oxygen to facilitate the water-assisted hydrolysis pathway (Figure 8). The overall reaction is:

$$
\mathrm{R}-\mathrm{CONH}_{2}+\mathrm{H}_{2} \mathrm{O}+\mathbf{N H}_{4}{ }^{+}+\mathbf{H}_{2} \mathbf{O} \rightarrow \mathrm{R}-\mathrm{COOH}+\mathrm{NH}_{3}+\mathbf{N H}_{4}{ }^{+}+\mathbf{H}_{2} \mathbf{O}
$$

The overall transition barrier of $27.2 \mathrm{kcal} / \mathrm{mol}$ is comparable with that with the protonated water-assisted pathway $(27.5 \mathrm{kcal} / \mathrm{mol})$. Note that the ammonia $\left(\mathrm{NH}_{3}\right)$ has a $\mathrm{pK}$ value of 9.25. Even under the neutral condition, nearly $99 \%$ of ammonia exists in the protonated state, e.g., $\mathrm{NH}_{4}{ }^{+}$. Therefore, this auto-accelerated effect from the ammonia production will be more significantly. Instead of acting as a neutral ammonia to accelerate the amide hydrolysis with the lowest transition barrier $(37.8 \mathrm{kcal} / \mathrm{mol}$, ref. Figure 6), the 
ammonium cation can further lower the transition barrier to $27.2 \mathrm{kcal} / \mathrm{mol}$ through the protonated water-assisted pathway, even under the neutral condition.

\subsection{Cation-Catalyzed Water-Assisted Mechanism}

In both protonated water-assisted and ammonium-catalyzed water-assisted pathways, the initial attacking of positively charged species on the carbonyl oxygen plays a significant role. Upon protonated, the carbonyl carbon becomes more positively charged, which substantially weaken the $\mathrm{C}-\mathrm{N}$ bond to facilitate the release of the $-\mathrm{NH} 3$ group. This result suggests that the presence of divalent cations such as $\mathrm{Ca}^{+2}$ or $\mathrm{Mg}^{+2}$ that can also attack to the carbonyl oxygen to catalyze the amide hydrolysis reaction (Figure 9). Indeed, the calculated transition barrier for the $\mathrm{Ca}^{2+}$-catalyzed water-assisted hydrolysis reaction has a very low value of $11.5+6.3=17.8 \mathrm{kcal} / \mathrm{mol}$. This result indicates that cations such as $\mathrm{Ca}^{2+}$ can not only act as a sink to precipitate HPAM, it can also catalyze the hydrolysis reaction to aggravate the formation of carbonyl group on HPAM.

\section{Conclusion}

Thermal stability of PAM/HPAM under HT/HS environments is one of the most important factors preventing widespread oilfield applications of PAM chemicals in harsh reservoir conditions. Structural modifications of PAM to form substituted and/or associated polymers have shown potentials to improve their thermal stability [43-46]. For example, substitutions of the $\mathrm{H}$-atom at the $\mathrm{NH}_{2}$ group with more shear-resistant functional groups such as longer alkyl chains and N-substitutes offer higher thermal stability in solution [47]. Water-soluble hydrophobically associating polymers contain a small number of hydrophobic groups directly attached to the polymer backbone. In aqueous solutions, these add-on hydrophobic groups have potential to associate resulting in an increasing solution viscosity [48-51]. Fundamental understanding of the basic chemistry related to the amide hydrolysis mechanism is of great importance to the molecular design and syntheses of modified PAM and their oilfield applications, particularly under HT/HS reservoir conditions.

In Table 1, we list all calculated transition barriers of the amide hydrolysis under different conditions from this study. Highlights of results are as follows:

- Both base- and acid-catalyzed reactions have transition barriers in range of 20 30 $\mathrm{kcal} / \mathrm{mol}$, which are much lower than the un-catalyzed reactions $(40 \sim 50 \mathrm{kcal} / \mathrm{mol})$ 
under the neutral condition. These results are consistent with the experimental observations that thermal stability of PAM polymers is very sensitive to salinity and $\mathrm{pH}$ of the aqueous solution.

- Both water and ammonia molecules can assist the amide hydrolysis. Because ammonia is one of end products of the hydrolysis reaction, the reaction is considered as auto-accelerated that the continuous accumulation of ammonia (or in its ionic ammonium form) will aggravate the degree of hydrolysis of PAM.

- The initial interaction of the positive species with the carbonyl oxygen is an important step to further lower the transition barrier of the water-assisted hydrolysis. The weaker $\mathrm{C}-\mathrm{N}$ bond resulting from more positively charged carbonyl carbon is considered as one of the reasons for the lowering barriers. Interactions of positively charged species with the carbonyl oxygen could occur from the O-protonation initiated from $\mathrm{H}_{3} \mathrm{O}^{+}$under the acidic condition, or from $\mathrm{NH}_{4}{ }^{+}$produced from hydrolysis, or in the presence of different concentrations of divalent cations such as $\mathrm{Ca}^{+2}, \mathrm{Mg}^{+2}$.

- In principal, the PAM hydrolysis could be slowed down if we can protect the carbonyl oxygen from attacking of the positive species. For instance, molecular modification of PAM/HPAM could be done by introducing the steric hindrance effects to prevent carbonyl oxygen from exposure, or by designing bridging groups to link the carbonyl oxygen with neighboring groups.

- Water-assisted pathway also plays an important role in the amide hydrolysis reaction. Therefore, by introducing the hydrophobic functional groups, such as Diacetone Acrylamide (DAAM), 2-Acrylamido-2-methylpropane sulfonic acid (AMPS), or NVinylpyrrolidone (NVP), onto PAM/HPAM polymers, we would expect to increase the entropy penalty for bringing the second water molecule into reaction, such that to slow down the amide hydrolysis reaction.

- The divalent cations such as $\mathrm{Ca}^{2+}$ and $\mathrm{Mg}^{2+}$ presented in brines have significantly adverse impacts on the thermal stability of PAM/HPAM. These cations not only can form complexes (gels or precipitates) with the carboxylic groups with HAPM to alter their rheological and phase properties, they can also catalyze the amide hydrolysis reaction to increase the degree of hydrolysis of PAM/HPAM polymers. In order to 
apply PAM/HPAM polymers in high-temperature/high-salinity (HT/HS) reservoir conditions, it is important to mitigate cationic effects on hydrolysis and stability. This can also be achieved by the addition of certain amounts of cation scavengers such as sodium sulfate $\left(\mathrm{Na}_{2} \mathrm{SO}_{4}\right)$, low-molecular weight PAM/HPAM or acetic acid to react with divalent cations.

\section{Acknowledgement}

This work was conducted as part of the molecular design program for the advanced chemicals in the oilfield applications in the Power Environmental Energy Research Institute (PEER Institute). Part of this program is supported through the Joint Industrial Project (JIP) of “Advanced Chemical Enhanced Oil Recovery Technologies”. Financial support from U.S. Department of Energy (DOE) through Research Partnership to Secure Energy for America (RPSEA) under agreement 10123-03 is high also appreciated.

Table 1: Summary of the Calculated Activation Energies of the Amide Hydrolysis of PAM under Different Conditions. All energies are taken at the room temperature $\mathrm{T}=298.15 \mathrm{~K}$ and ambient pressure (1 atm).

\begin{tabular}{|c|c|c|}
\hline \multirow{3}{*}{$\begin{array}{c}\text { Reaction } \\
\text { Condition }\end{array}$} & Reaction Pathways & $\begin{array}{c}\text { Activation Energy } \\
\text { (kcal/mol) }\end{array}$ \\
\hline \multirow{4}{*}{ Neutral } & Stepwise & 54.4 \\
\cline { 2 - 3 } & Concerted & 57.8 \\
\cline { 2 - 3 } & Water Assisted & 42.4 \\
\cline { 2 - 3 } & Concerted Ammonium Assisted & 46.8 \\
\cline { 2 - 3 } & Stepwise Ammonium Assisted & 37.8 \\
\cline { 2 - 3 } & Water-assisted Ammonium Catalyzed & $\mathbf{2 7 . 2}$ \\
\hline \multirow{2}{*}{ Basic } & Water-assisted Ca ${ }^{+2}$-catalyzed & $\mathbf{1 7 . 8}$ \\
\hline \multirow{3}{*}{ Acidic } & General Stepwise & $\mathbf{3 1 . 5}$ \\
\cline { 2 - 3 } & O-protonation & 46.2 \\
\cline { 2 - 3 } & N-protonation & 41.8 \\
\cline { 2 - 3 } & Water Assisted & $\mathbf{2 7 . 5}$ \\
\hline
\end{tabular}




\section{References}

[1] Chatterji J, Borchardt JK. Applications of water-soluble polymers in the oil fields. J Pet Technol 1981;33:2042-56.

[2] Bock J, Pace SJ, Schulz DN. Enhanced Oil Recovery with Hydrophobically Associating Polymers containing N-vinyl Pyrrolidone Functionality. US Patent. 4,709,759. 1987.

[3] Sorbie KS. Polymer-Improved Oil Recovery. CRC Press: Boca Raton, Florida; 1991.

[4] Aften CW, Watson WP. Improved friction reducer for hydraulic fracturing. SPE118747, SPE Hydraulic Fracturing Technology: Woodlands, TX; 2009.

[5] Aften CW. Study of friction reducers for recycled stimulation fluids in environmentally sensitive regions. SPE-138984, SPE Eastern Regional Meeting: Morgantown; WV 2010.

[6] Aften CW. Friction reducers fresh rheological insights married to performance. SPE171025, SPE Eastern Regional Meeting; Charleston: 2014.

[7] Shupe RD. Chemical stability of polyacrylamide polymers. J of Petro Techno 1981:1513-29.

[8] Rylos RG. Chemical stability limits of water-soluble polymers used in oil recovery processes. SPE Reservoir Eng. 1988:23-34.

[9] Audibert A, Argillier JF. Thermal stability of sulfonated polymers. SPE-28953, SPE Int Symp Oilfield Chem; San Antonio, TX: 1996.

[10] Ikegami A, Imai, N. Precipitation of polyelectrolytes by salts. J Poly Sci $1962 ; 56: 133-52$.

[11] Schwartz T, Francois J. Solubility limits of partially hydrolyzed polyacrylamides in the presence of divalent ions. Makromol Chem 1981;182:2775-85.

[12] Moradi-Araghi A, Doe PH. Hydrolysis and precipitation of polyacrylamides in harsh brines at elevated temperature. SPE Reserve Engineering, 1987;2(2):189-97.

[13] Zaitoun A, Potie B. Limit conditions for the use of hydrolyzed polyacrylamides in brines containing divalent ions. SPE-11785, SPE Int Symp Oilfield Geothermal Chem; Denver, CO; 1983. 
[14] Nasr-El-Din HA, Hawkins BF, Green KA. Viscosity behavior of alkaline, surfactant, polyacrylamide solutions used for enhanced oil recovery. SPE-21028, SPE Int Symp Oilfield Chem; Anaheim, CA: 1991.

[15] Bonapasta AA, Buda F, Colombet P. Interaction between Ca ions and poly(acrylic acid) chains in macro-defect-free cements: a theoretical study. Chem Mater 2001;13:64-70.

[16] Seright RS, Campbell AR, Mozley PS, Han P. Stability of partially hydrolyzed polyacrylamides at elevated temperatures in the absence of divalent cations. SPE Journal 2010;15(2):341-8.

[17] Kahne D, Still WC. Hydrolysis of a peptide bond in neutral water. J Am Chem Soc 1988;110:7529-34.

[18] Brown RS, Bennet AJ. Ślebocka-Tilk H. Recent perspectives concerning the mechanism of $\mathrm{H}_{3} \mathrm{O}^{+}$- and $\mathrm{OH}^{-}$-promoted amide hydrolysis. Acc Chem Res 1992;25:481-8.

[19] Brown RS. In: The amide linkage: Selected structural aspects in chemistry, biochemistry and materials science. Greenberg A, Breneman CM, Liebman JF Editors. Wiley-Interscience; New York; 2000.

[20] Guthrie JP. Hydration of carboxamides. Evaluation of the free energy change for addition of water to acetamide and formamide derivatives. J Am Chem Soc 1974;96:3608-15.

[21] Ślebocka-Tilk H, Bennet AJ, Hogg HJ, Brown RS. Predominant ${ }^{18} \mathrm{O}$ exchange accompanying base hydrolysis of a tertiary toluamide: N-Ethyl-N(trifluoroethy1)toluamide. Assessment of the factors that influence partitioning of anionic tetrahedral intermediates. J Am Chem Soc 1991;113:1288-94.

[22] Schowen RL, Zuorick GW. Amide hydrolysis. Superimposed general base catalysis in the cleavage anilides. J Am Chem Soc 1966;88:1223-25.

[23] O'brien JF, Pranata J. Ab initio study of the base-promoted hydrolysis of Nmethylformamide. J Phys Chem 1995;99:12759-63.

[24] Bakowies D, Kollman PA. Theoretical study of base-catalyzed amide hydrolysis: gas- and aqueous-phase hydrolysis for formamide. J Am Chem Soc 1999;121(24):5712-26. 
[25] Ślebocka-Tilk H, Neverov AA, Brown RS. Proton inventory study of the basecatalyzed hydrolysis of formamide. Consideration of the nucleophilic and general base mechanisms. J Am Chem Soc 2003;125:1851-58.

[26] Xiong Y, Zhan CG. Theoretical studies of the transition-state structures and free energy barriers for base-catalyzed hydrolysis of amides. J Phys Chem A 2006;110: 12644-52.

[27] Cohen T, Lipowitz J. Acid-catalyzed amide hydrolysis assisted by a neighboring amide group. J Am Chem Soc 1964;86(24):5611-16.

[28] Krug JP, Popelier PLA, Bader RFW. Theoretical study of neutral and of acid and base promoted hydrolysis of formamide. J Phys Chem 1992;96:7604-16.

[29] Zahn D. Theoretical study of the mechanisms of acid-catalyzed amide hydrolysis in aqueous solution. J Phys Chem B 2003;107(44):12303-6.

[30] Manojkumar TK, Suh SB, Oh KS, Cho SJ, Cui C, Zhang X, Kim KS. Theoretical studies on the mechanism of acid-promoted hydrolysis of $\mathrm{N}$-formylaziridine in comparison with formamide. J Org Chem 2005;70(7):2651-59.

[31] Bolton PD. Hydrolysis of amides. II. Substituent effects in dilute acid and alkali. Aust J Chem 1966;19:1013-21.

[32] Bolton PD, Jackson GI. Hydrolysis of amides. V. Alkaline hydrolysis of alkylsubstituted amides. Aust J Chem 1971;24:969-74.

[33] Antonczak S, Ruiz-López M, Rivail JL. Ab initio analysis of water-assisted reaction mechanisms in amide hydrolysis. J Am Chem Soc 1994;116(9):3912-21.

[34] Antonczak S, Ruiz-López M, Rivail JL. The hydrolysis mechanism of formamide revisited: comparison between ab initio, semiempirical and DFT results. J Mol Model 1997;3:434-42.

[35] Radzicka A, Wolfenden R. Rates of uncatalyzed peptide bond hydrolysis in neutral solution and the transition state affinities of proteases. J Am Chem Soc 1996;118:6105-09.

[36] Oie T, Loew GH, Burt SK, Binkley JS, MacElroy RD. Quantum chemical studies of a model for peptide bond formation: formation of formamide and water from ammonia and formic acid. J Am Chem Soc 1982;104(23):6169-74. 
[37] Oie T, Loew GH, Burt SK, MacElroy RD. Quantum chemical studies of a model for peptide bond formation. 2. role of amide catalyst in formation of formamide and water from ammonia and formic acid. J Am Chem Soc 1983;105(8):2221-27.

[38] Jensen JH, Baldridge KK, Gordon MS. Uncataiyzed Peptide Bond Formation in the Gas Phase. J Phys Chem 1992;96:8340-51.

[39] Nagase K, Sakaguchi, K. Alkaline hydrolysis of Polycrylamide. J Polym Sci Part A $1972 ; 3: 2475-82$.

[40] Kallies B, Mitzner R. Models of water-assisted hydrolyses of methyl formate, formamide, and urea from combined DFT-SCRF calculations. J Mol Model 1998;4:183-96.

[41] Mujika JI, Mercero JM, Lopez X. Water-promoted hydrolysis of a highly twisted amide: rate acceleration caused by the twist of the amide bond. J Am Chem Soc 2005;127:4445-53.

[42] Almerindo GI, Pliedo R Jr. Ab initio investigation of the kinetics and mechanism of the neutral hydrolysis of formamide in aqueous solution. J Braz Chem Soc 2007;18(4):696-702.

[43] Sawant S, Morawetz H. Microstructure, neighboring group inhibition, and electrostatic effects in the base-catalyzed degradation of polyacrylamide. Macromolecules, 1984;17(11):2427-31.

[44] Khune GD, Donaruma LG, Hatch MJ, Kilmer NH, Shepitka JS, Martin FD. Modified acrylamide polymers for enhanced oil recovery. J Appl Pol Sci $1985 ; 30: 875-85$.

[45] Taylor KC, Nasr-El-Din HA. Water-soluble hydrophobically associating polymers for improved oil recovery: a literature review. J Petro Sci \& Eng 1998;19:265-80.

[46] Sabhapondit A, Borthakur A, Haque I. Characterization of acrylamide polymers for enhanced oil recovery. J Appl Pol Sci 2003;87:1869-79.

[47] Thompson K, Michielsen S. Novel synthesis of N-substituted polyacrylamides: derivatization of Poly(acrylic acid) with amines using a triazine-based condensing reagent. J Appl Polym Sci 2006;44:126-36. 
[48] McCormick CL, Johnson CB. Structurally tailored macromolecules for mobility control in enhanced oil recovery. In: Stahl GA, Schulz DN, Editors. Water-soluble polymers for petroleum recovery. Plenum Press: New York; 1988.

[49] McCormick CL, Johnson CB. Synthetically structured water-soluble copolymers: Associations by hydrophobic or ionic mechanisms. In: Polymers in aqueous media: Performance through association. Advanced in Chemistry Series No. 223. American Chemical Society: Washington, DC; 1989.

[50] Biggs S, Hill A, Candau F. Copolymerization of acrylamide and a hydrophobic monomer in an aqueous micellar medium: Effect of the surfactant on the copolymer microstructure. J Phys Chem 1992;96:1505-11.

[51] Uhl JT, Ching TY, Bae JH. A laboratory study of new, surfactant-containing polymers for high-salinity reservoirs. SPE-26400, SPE Proc $68^{\text {th }}$ Ann Tech Conf and Exhib; Houston, TX; 1993. 


\section{Figure 1}

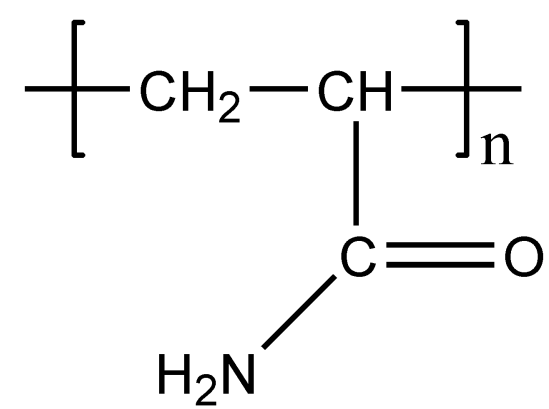

Polyacrylamide (PAM)

(a)

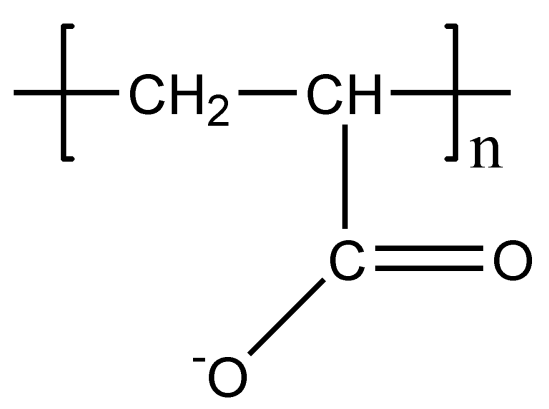

Hydrolyzed PAM

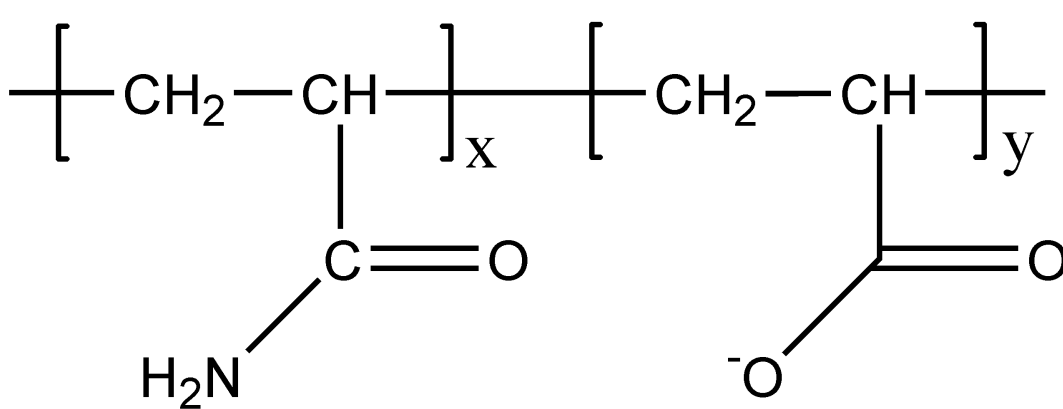

Partially Hydrolyzed Polyacrylamide (HPAM)

(b)

(c) 


\section{Figure 2}

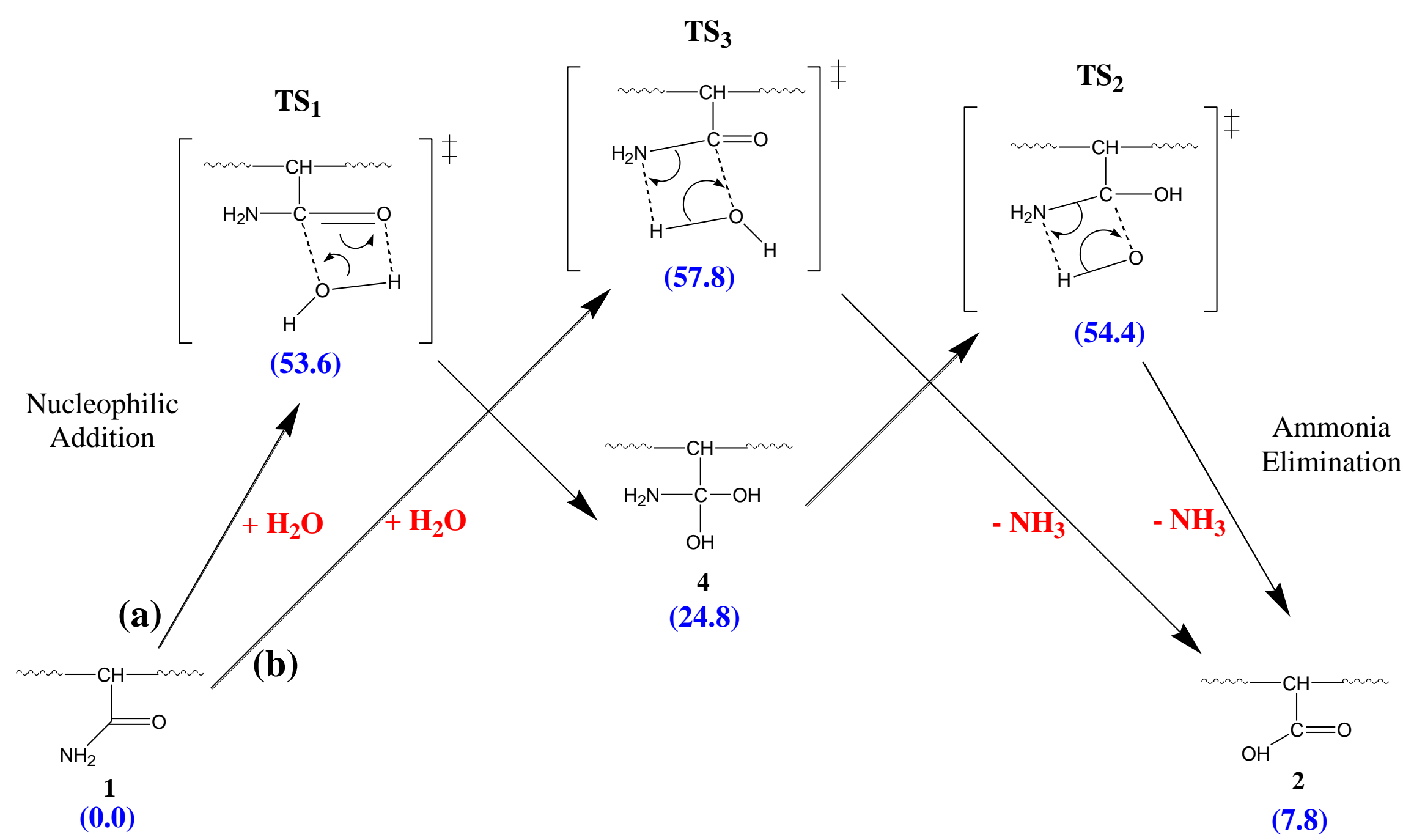

Figure 2: Reaction pathways of the amide hydrolysis under the neutral condition for both the (a) stepwise and (b) concerted mechanisms. The numbers inside the parenthesis are the relative energies related that of the separated molecules. 


\section{Figure 3}

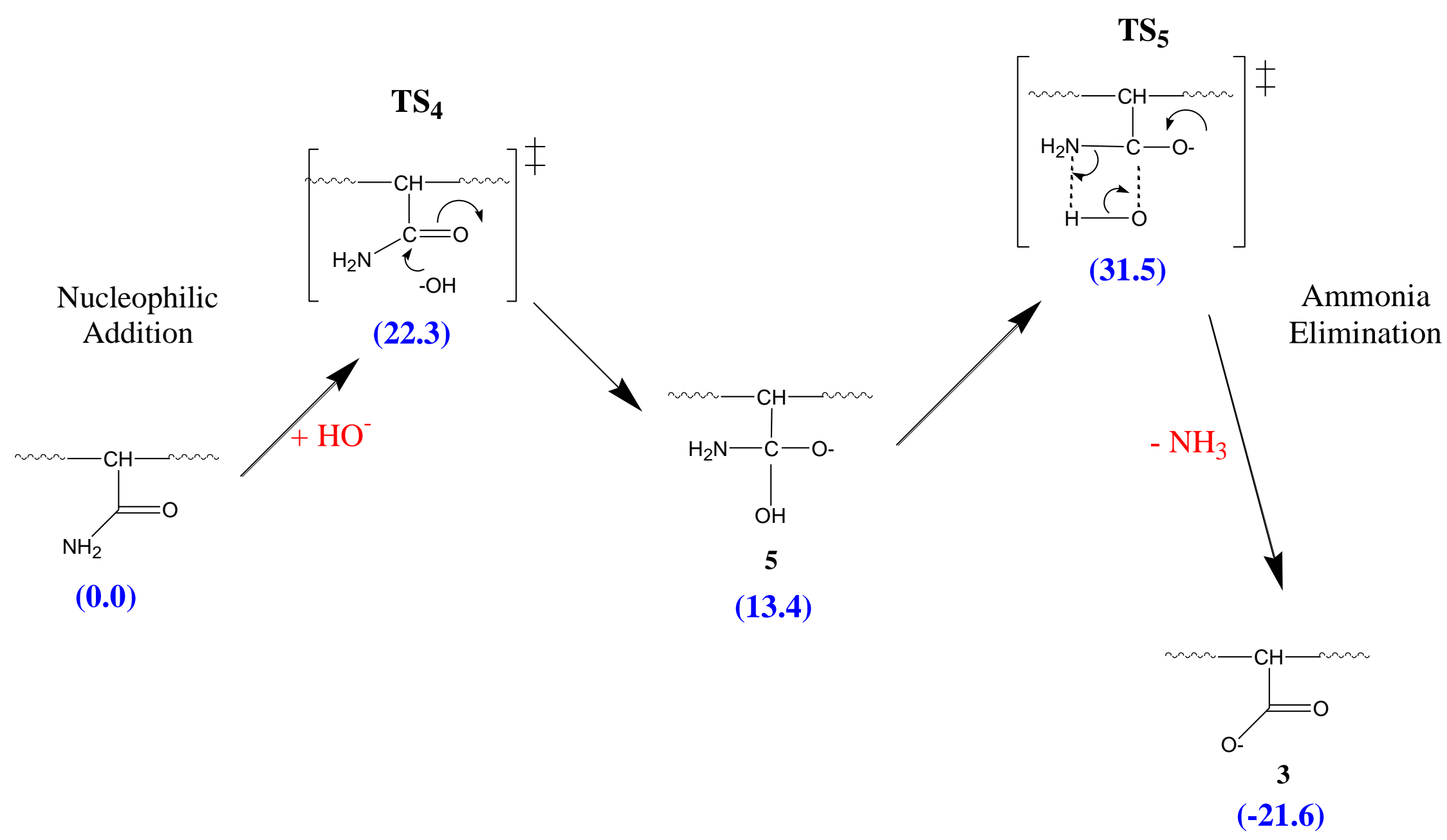

Figure 3: Reaction pathway of the amide hydrolysis reaction under base-catalyzed condition by the stepwise mechanism. 


\section{Figure 4(a)}

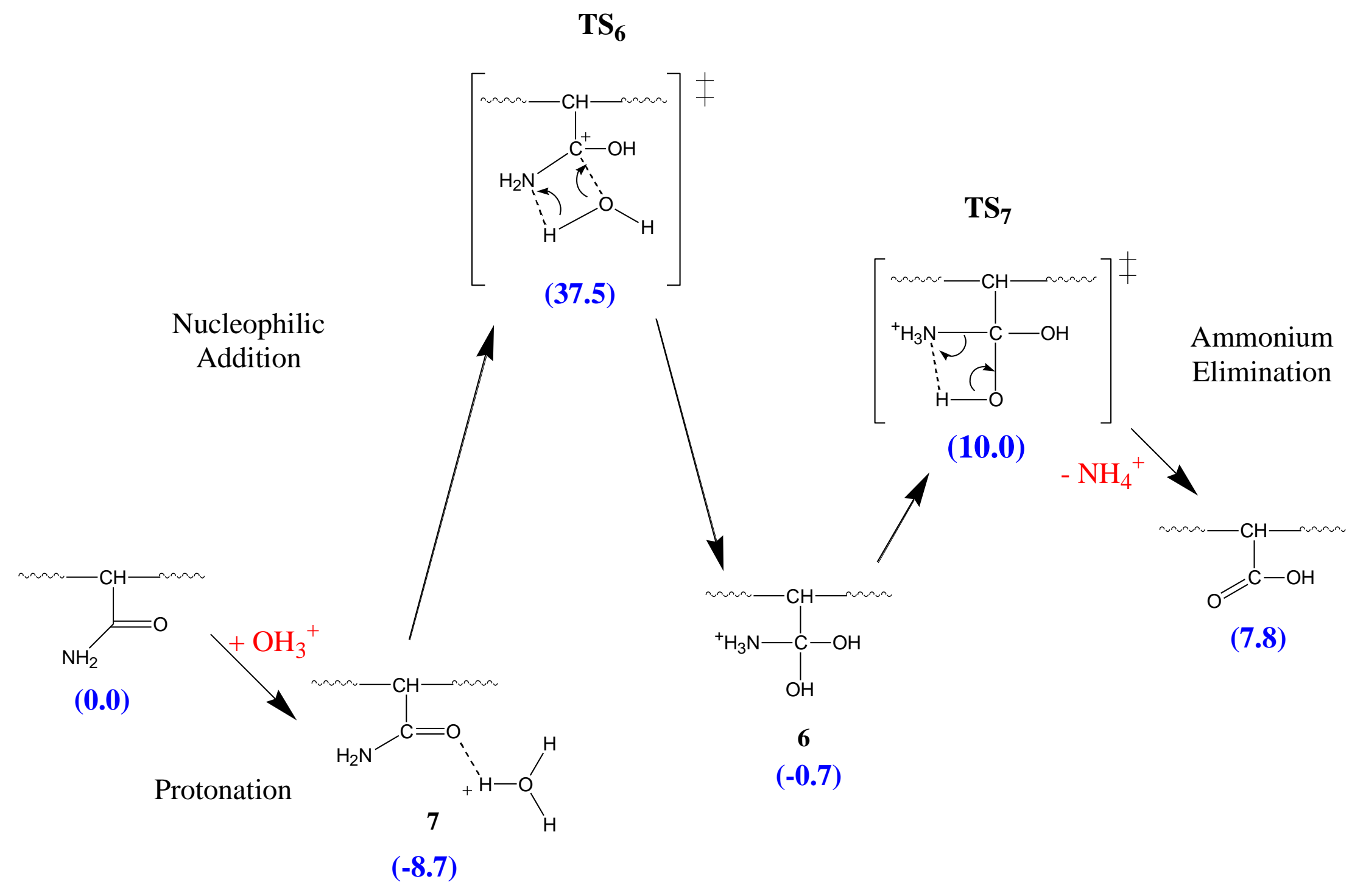

Figure 4(a) 


\section{Figure 4(b)}

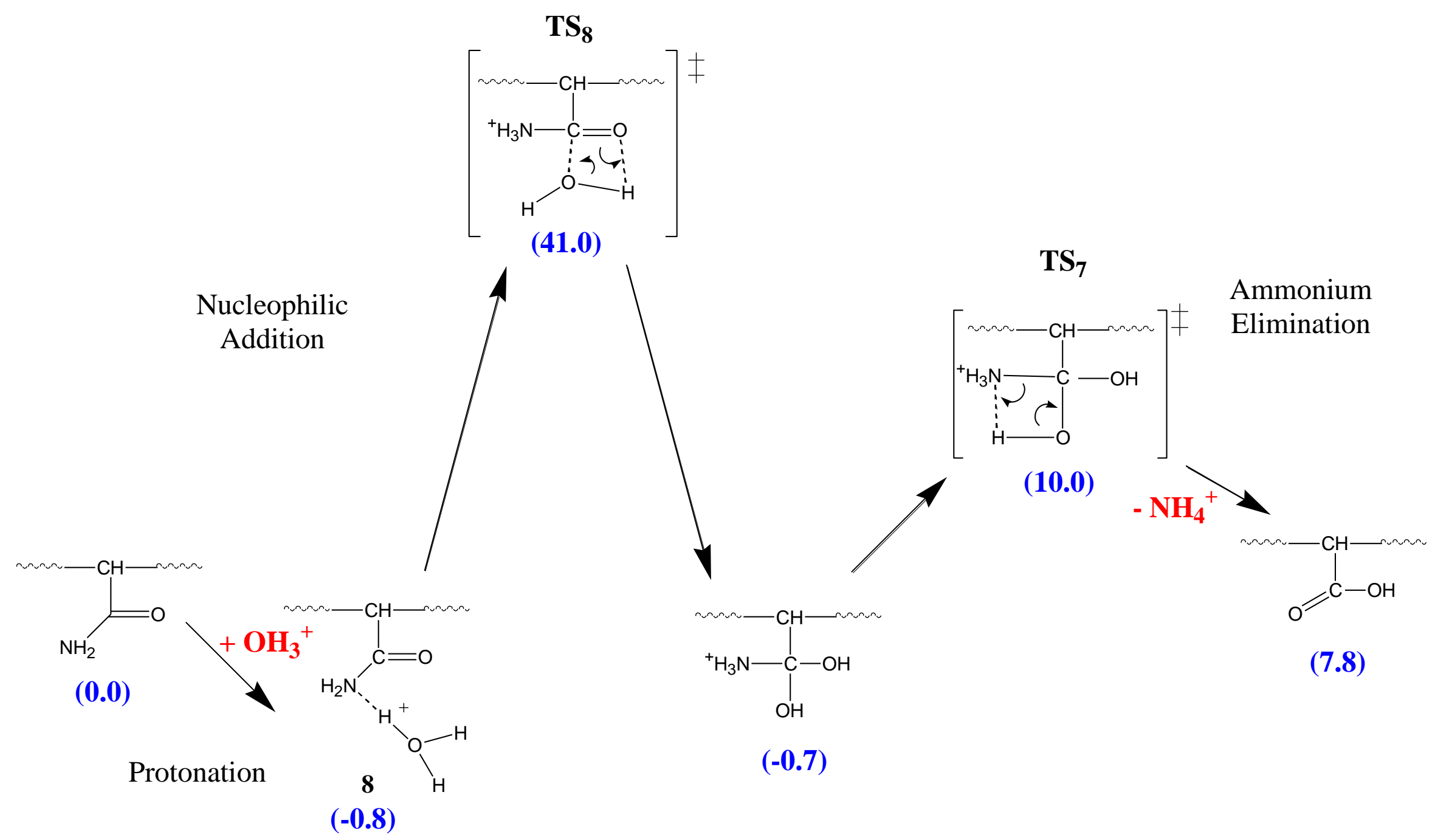

Figure 4: Reaction pathways of the amide hydrolysis reaction under acidic conditions initiated from (a) O-Protonation and (b) N-Protonation. 


\section{Figure 5}

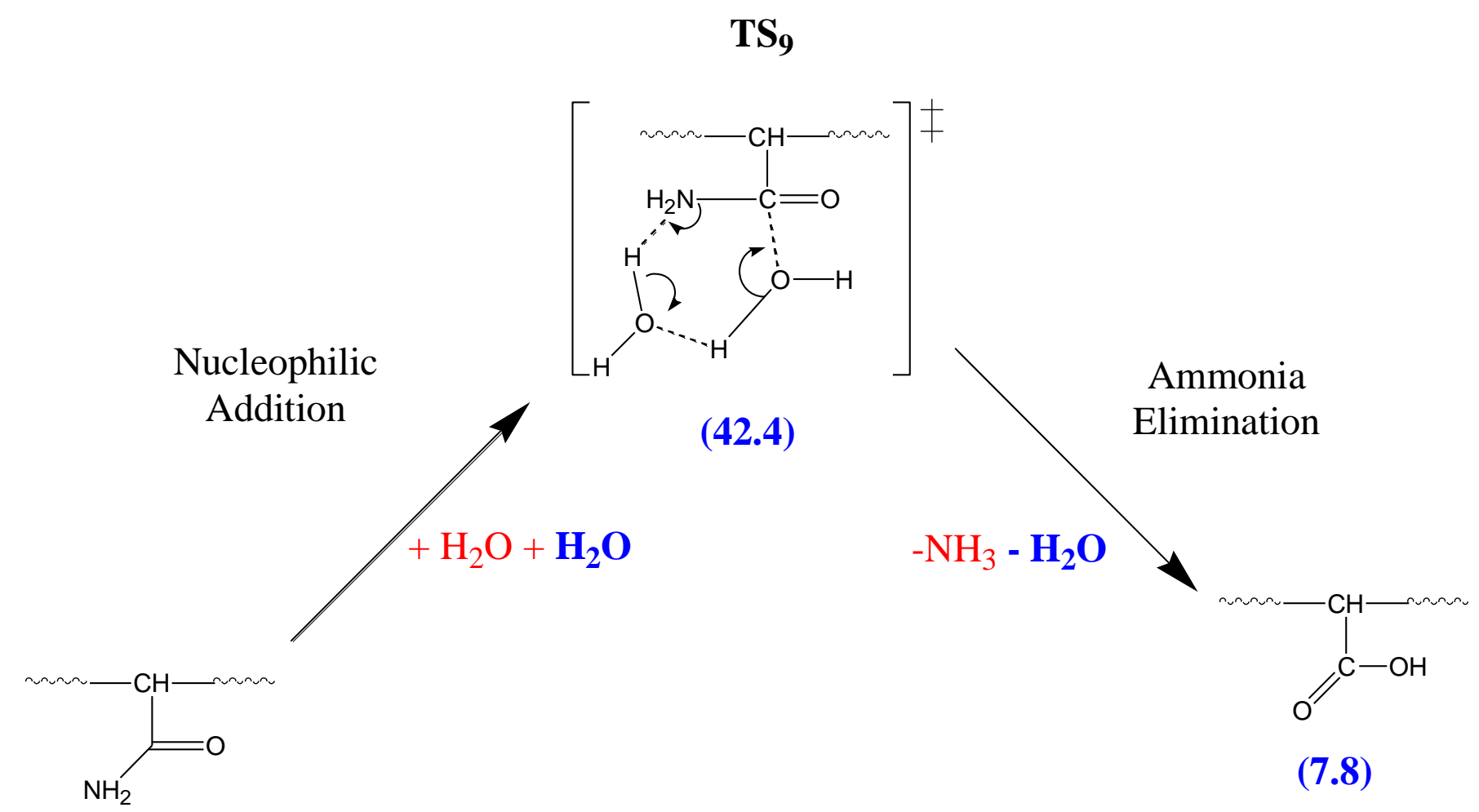

$(\mathbf{0 . 0})$

Figure 5: Reaction pathway of the water-assisted hydrolysis reaction under the neutral condition. 


\section{Figure 6}

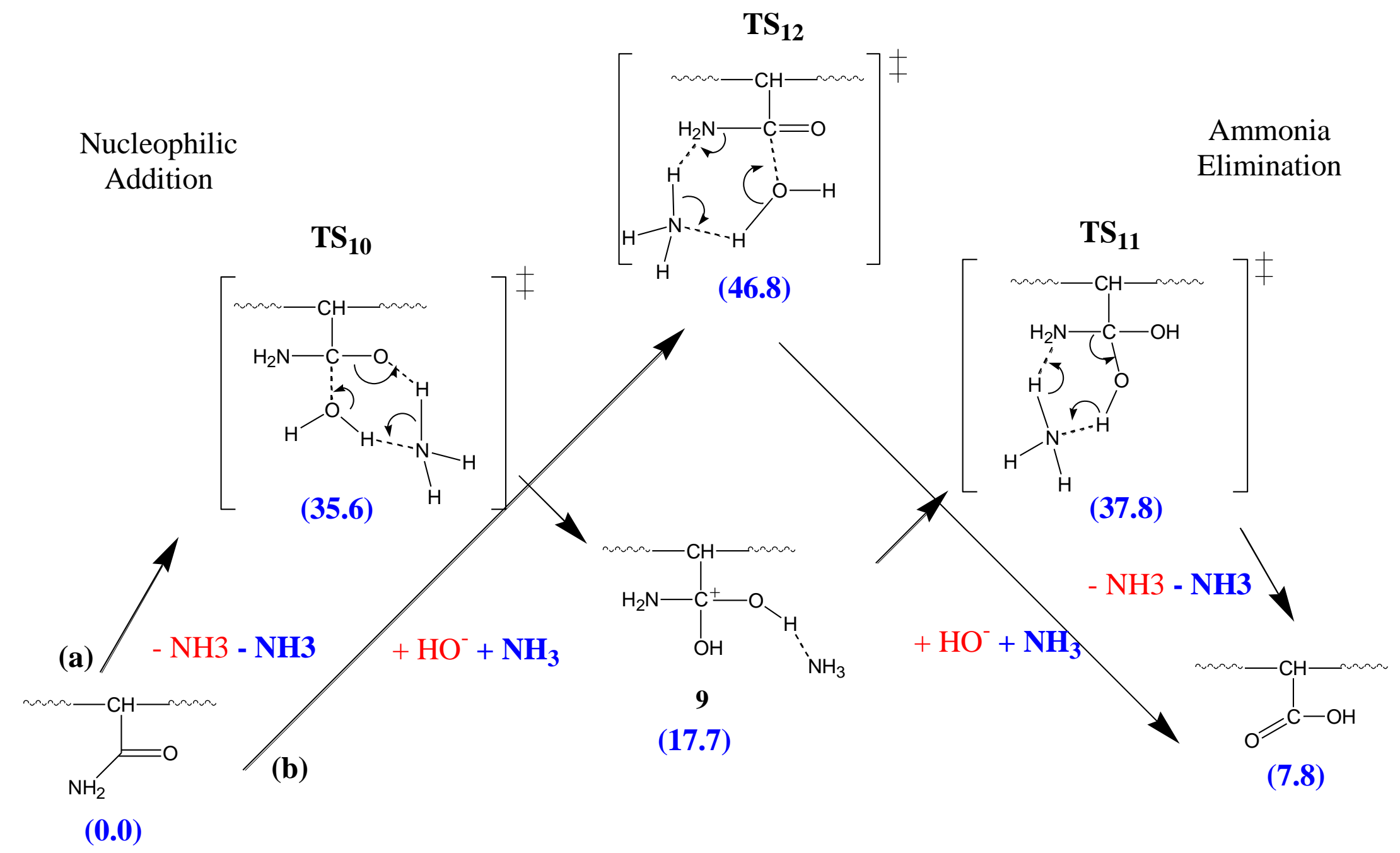

Figure 6: Reaction pathways of the ammonia-assisted hydrolysis reaction under the neutral condition (a) the stepwise pathway and (b) the concerted pathway. 


\section{Figure 7}

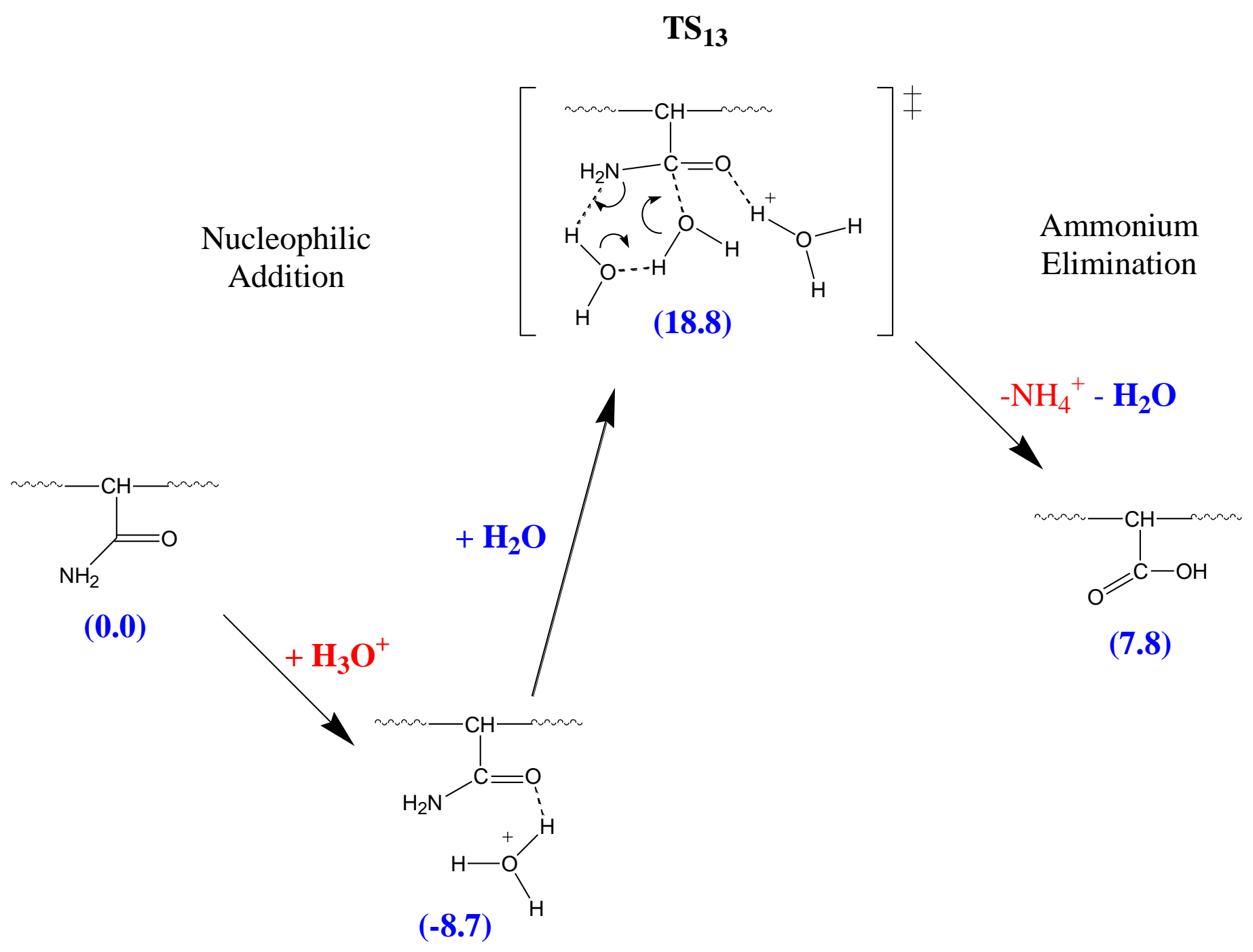

Figure 7: Reaction pathway and the calculated energy profile of the water-assisted O-protonation hydrolysis reaction. 


\section{Figure 8}

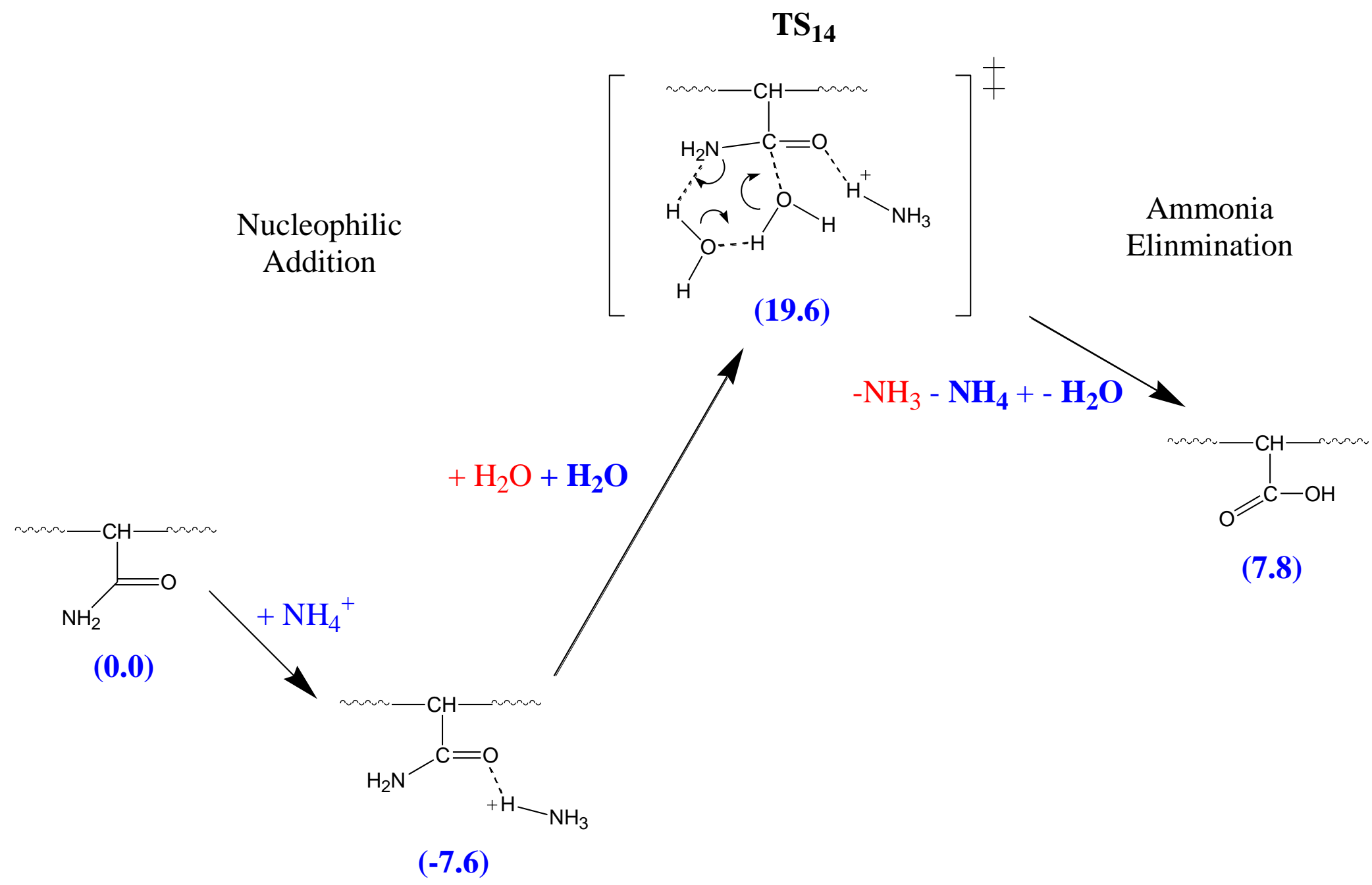

Figure 8: Reaction pathway of the water-assisted hydrolysis pathway initiated from the interaction of ammonium ion $\left(\mathrm{NH}_{4}{ }^{+}\right)$on the $\mathrm{O}$-atom. 


\section{Figure 9}

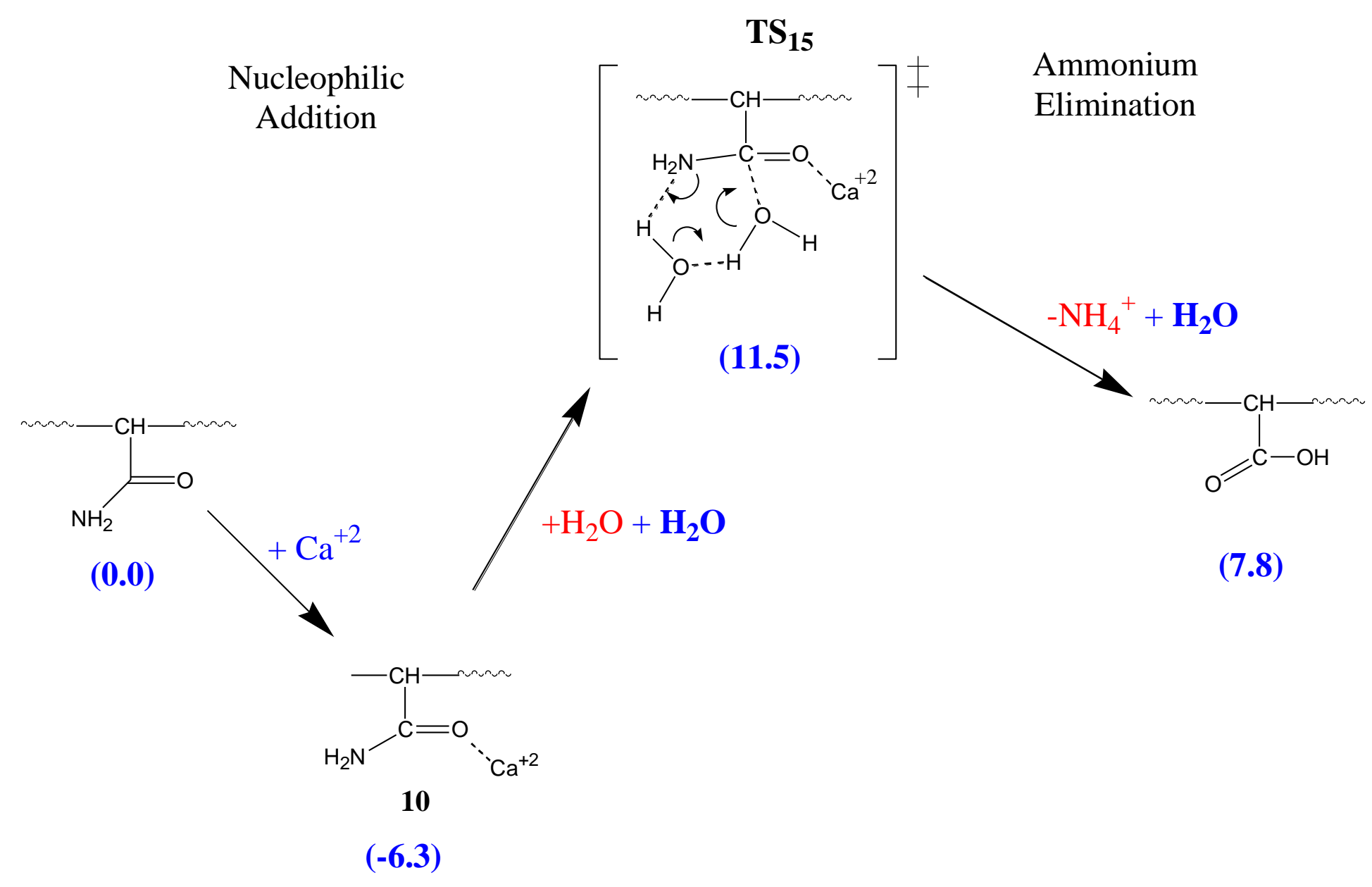

Figure 9: Reaction pathway and the calculated energy profile of water-assisted hydrolysis pathway initiated from the $\mathrm{Ca}^{2+}$ cation attacking on the $\mathrm{O}$-atom. 